\title{
The Effectiveness of Behaviour Based Safety (BBS) in Accident Prevention at a Pine Timber Processing Plant in Nyanga District, Zimbabwe
}

\author{
Steven Jerie ${ }^{a^{*}}$, Baldwin Jenya ${ }^{b}$ \\ a Midlands State University, Gweru, Zimbabwe. \\ ${ }^{*}$ Corresponding author's email address: sjerie2014@gmail.com
}

\section{A R T I C L E I N F O}

Received: 20-05-2017

Accepted: 07-06-2017

Available online: 24-07-2017

\section{Keywords:}

Behaviour, safety, accident prevention, pine timber processing, Personal protective clothing

JEL Classification: G18; D11; K32.

\section{A B S T R A C T}

The aim of this study was to assess the effectiveness of Behaviour Based Modelling (BBM) in the timber processing operations at a pine timber processing plant in Nyanga district in Eastern Zimbabwe. A detailed descriptive study was undertaken on the effectiveness of BBM in the timber processing operations. A sample size of $20 \%$ of all the 600 employees directly involved in timber processing operations was used in data collection. Direct field observations, interviews and questionnaires surveys were used as primary sources of data collection. Secondary data was acquired from the division's local clinic and the Safety, Health and Environment (SHE) department at the timber processing plant. Data collected was analysed using the statistical and descriptive methods. The study showed that BBM is accomplishing its intended goals although management support could increase with the prime focus centered on timber processing operations. Behaviour Based Modelling has changed employee attitudes in dealing with occupational related accidents and environmental pollution through the "brother's keeper" attitude. Before the implementation of Behaviour Based Management, the pine processing plant recorded high numbers (triple figured digits) of near misses and occupational related accidents. However, the introduction of Behaviour Based Modelling resulted in the recording of double figured digits in occupational related accidents and zero major environmental spillages by the end of 2016. Improvements on the existing operational procedures of Behaviour Based Modelling could, however, improve its effectiveness. The Safety, Health and Environment department should ensure that employees have the right to refuse to work under unsafe and unhealthy work conditions.

(C) 2017 The Authors. This is an open access article under the terms of the Creative Commons Attribution License 4.0, which allows use, distribution and reproduction in any medium, provided the original work is properly cited.

DOI: http://dx.doi.org/10.18533/rss.v2i6.103

ISSN 2378-8569(Print), ISSN 2378-8550(Online)

\section{Introduction}

Fleming and Lardner (2005) defined Behaviour Based Modeling as an approach to occupational safety and environmental management that focuses on workers' behaviour as the cause of most work-related injuries, illnesses and environmental degradation. Byron (2002) also stipulates that Behaviour Based Modelling is about promoting safe behaviour at work which turns systems and procedures into reality. Lardner (2002) concurs that on their own, good systems do not offer successful health, safety and environmental management. He further noted that the level of success in environmental management and occupational health and safety programmes is determined by how the organisations "live" their systems hence Behaviour Based Modelling. According to Daniels (2004) Behaviour Based Modeling is a brainchild of Behaviour Based Safety (BBS) 
modified to accommodate environmental management issues. Bandura (2007) argues that in identifying correct behaviour, determining appropriate procedures and reinforcing health, safety and environmental management there is need to involve all stakeholders.

There are, however, varying concerns on global scales on whether Behaviour Based Modeling is the most ideal tool in compacting occupational health and safety issues and environmental problems as compared to other methods such as Behaviour Based Safety or the mere provision of personal protective equipment (PPE). Statistics shows that up to $95 \%$ of accidents are as a result of at risk behaviour and as a panacea to this most organisations world over have adopted Behaviour Based Modelling. Multinational companies such as Linbeck Construction Company and CITIGO petroleum of London have also implemented Behaviour Based Modeling, and this serves to demonstrate its universality in applicability. World over, different organisations, as argued by Fishwick, Ormond and Chem (1998) have realized that it is paramount to have employees actively caring for each other and the environment such that they need to keep an eye to notice unsafe behaviour and provide immediate feedback. Such integrated efforts have also been noted by Fox, Hopkins and Anger (2002) as crucial in trying to curb occupational related accidents and environmental spillages world over.

Occupational related accidents and industrial environmental problems remain a concern world over. An analysis on the effectiveness of BBM at Nyanga pine becomes significant to establish whether it is the best tool to curb the identified concerns. The research is hoped to benefit the timber processing industry and other organisations which have adopted BBM. Results from this research will demonstrate whether BBM is effective in transforming employees' attitude in executing various operations and environmental management at the timber processing plant thereby providing information to other research alike. The outcome of the study will act as a benchmark for research on which related research can further reference on. According to, Cooper (2000) best systems or controls available are no guarantee that undesirable incidents will not occur. The research will draw a conclusion on whether BBM is achieving its intended goals and hence providing a panacea which can be recommended to organisations by the NSSA of Zimbabwe on how to reduce occupational accidents. The research is significant as it is hoped to benefit the cooperate world in establishing whether BBM is the best method of eliminating occupational related accidents and health concerns while reducing environmental problems in timber processing. The domino effect of this research can also be used on advisory basis by the ministries of public service labour and social welfare, the ministry of industry and the ministry of environment in policy formulation. The Environmental Management Agency (EMA) of Zimbabwe can also benefit from the research through the adoption of BBM in environmental management at national level.

The outcome of the study will act as a benchmark for research on which related research can further reference on. According to, Cooper (2000) best systems or controls available are no guarantee that undesirable incidents will not occur. The research draws conclusions on whether Behaviour Based Management is achieving its intended goals and hence providing a panacea which can be recommended to organisations by the National Social Security Authority of Zimbabwe on how to reduce occupational accidents. The research is intended to assist the corporate world in establishing whether Behaviour Based Modelling is the best method of eliminating occupation related accidents and health concerns while reducing environmental problems in timber processing. The domino effect of this research can also be used on advisory basis by the ministries of public service labour and social welfare, the ministry of industry and the ministry of environment in policy formulation. The Environmental Management Agency (EMA) of Zimbabwe can also benefit from the research through the adoption of Behaviour Based Modelling in environmental management at national level.

\section{Literature review}

\subsection{Conceptualising behaviour based modelling}

Empirical research reveals that $80-95 \%$ of occupational accidents and industrial environmental problems are as a result of employee behaviour towards work (Cooper et al 2004). To correct this predicament it is paramount to change employee behaviour towards work and this is done through behaviour modelling. According to Horvath and Rudas (2010) behaviour modelling is the ability to transform and correct employee attitude towards the manner in which they execute day to day activities. Behaviour modelling is made applicable

CURRENT THINKING

Things happen,
accidents are part of life

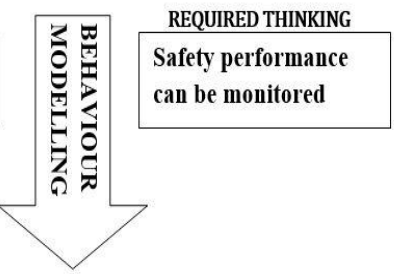

Figure 1: Conceptualisation of Behaviour Based Modelling. Adapted: Colman, Ezinah and Wezet (2007) and Herman (2000)

through the use of training courses, workshops and issuing of incentives to employees for outstanding occupational correct behaviour. The use of Occupational and Health Management Systems (OHMS), which incorporate behaviour modelling, can reduce or eliminate work related injuries (Colman, Ezinah and Wezet 2007). The concept of behaviour modelling can be illustrated with the aid of a diagram as shown in Figure 1. 


\subsection{Problems in implementing behaviour based modelling}

As postulated by Herman (2000) prior to behaviour modelling the general belief by employees was that accidents are a part of every working environment and that behaviour modelling has the ability to transform this to a situation where safety performance can be monitored. The same concept can also be employed in environmental management through the proactive rather than reactive approach in environmental management (Nhete 2000). This is made possible through behaviour modelling. According to Schutte (1998) the effectiveness of Behaviour Based Modelling depends on the ability to overcome the possible problems encountered during implementation stages. Lack of workforce support normally comes about because the management team, without consultation, imposes a system on the workforce (Colman, Ezinah and Wezet 2007).

In many instances, companies and organisations believe that bringing in a behavioural safety consultant to provide the management team with an overview briefing is enough to gain the required buy-in from all employees. Herman (2000) argues that it is vital to have the workforce participating in the decision making processes by being informed about what it is intended to yield, what it means to them on a day to day basis, and how they can help prior to starting the initiative. This offers the advantage of the workforce and line management of being able to ask searching questions and deciding whether or not it is something they wish to engage in. Lack of workforce support results in the ineffective implementation of Behaviour Based Modelling.

The problem of observation checklists not targeting the causal behaviour usually occurs because the accident records have not been analysed correctly, and or the people's perceptions have been allowed to dominate (McSween 2003). Examining the existing accident or near miss incident database and conducting a frequency count of the specific behaviour involved, and breaking these down by geographical location should direct the observation checklist. If the observation checklists fail to target the causing behaviour Behaviour Based Modelling may fail to yield the desired goals and thus not effective. According to Bello (2010), checklists should be used to ascertain the actual unsafe behaviours involved in incidents and to realise if accident records are less than adequate (as they often are) and do not specify the behaviors involved.

The failure to define the unsafe behaviour with precision is a very common problem with many behavioural safety systems (Hickman and Geller 2003). For example, according to Schutte (1998) the use of expressions such as, ' when welding personnel are using the correct procedures' as a behavioural checklist item. Defining what is meant by correct procedures becomes a problem as such items assume everybody knows what the correct procedures are. This undermines the effectiveness of Behaviour Based Modelling and hence behavioural systems tend to operationally define a workflow process or task. For each task, such operational definitions tend to include between 6-8 behaviours within the definition (Colman, Ezinah and Wezet 2007). The observation sampling should be undertaken at random times throughout the observing period so as to avoid a bias in results as argued by (Lane and Bachmann 1998).

Usually observations take place during the same time for example in a working environment involving night shift; observers may avoid the night shift and hence observe only during the day. This will result in a biased outcome which eventually affects the effectiveness of Behaviour Based Modelling. According to Fox, Hopkins and Anger (2009), the timing of each day's observation must be as unpredictable as possible, else what might be achieved is that people behave safely only for that particular time period.

Lack of regular feedback on safety and environmental performance monitoring due to the perception that people do not have the time can create a lack of workforce buy-in (Cooper et al. 2004). This is because workers believe line management does not view Behaviour Based Modelling as an appropriate weapon to reduce accidents. Behaviour Based Modelling requires detailed feedback to be given to the workforce on a regular interval for example monthly or quarterly basis as this will monitor its effectiveness. According to McAfee and Winn (1989) lack of regular feedback sessions will often lead to accusations that behavioural safety takes a lot of effort for very little 'payback', as the accident rate and the percentage safe scores remain static. A successful Behaviour Based Modelling is made possible through a sound regular feedback system.

In most organisations management considers production to be at the centre stage while sidelining safety and environmental management issues (Hickman and Geller 2003). Behaviour Based Modelling is not viewed as a part of the problem, in production and therefore sees limited support from management. When managers fail to realise the importance of Behaviour Based Modelling they do not allow workers time to conduct observations, encourage people to behave safely, facilitate the target setting and feedback sessions. The company will also deliberately fail to help in the implementation of any remedial action by aiding with paperwork and providing any necessary resources. 


\subsection{The value of behaviour based modelling}

Jones, Cox and Rycraft (2004), postulates that Behaviour Based Modelling has proved to be an effective tool for accident reduction at the workplace since 1984. Furthermore, Randy Klug director of health and safety at Rexan Beverages pointed out that they had a $100 \%$ accident reduction rate for four years since the implementation of Behaviour Based Modelling. Both the quantity and quality of participation in Behaviour Based Modelling activities depend on the numbers used to evaluate success or failure. The bottom line to measure the effectiveness of Behaviour Based Modelling is to record total injury rate (TIR). After recording the injuries then it is vital to compare them with the accident recorded before the implementation of Behaviour Based Modelling. Hickman and Geller (2003) propounded that an analysis of accident prevalence and environmental problems prior and post the implementation of BBM is essential in determining whether it is effective or not. The effectiveness of Behaviour Based Modelling tremendously relies on the gains attached and this is the ability to engage workers collaboratively in the improvement process. While impressive, almost all of these Behaviour Based Modelling initiatives have been implemented in various processing operations for example timber processing. While several small, well controlled studies have assessed the effectiveness of some behavioural management techniques in operations for example those by Jones, Cox and Rycraft (2004), there remains a need to assess the effectiveness of a comprehensive Behaviour Based Modelling program within organisations. Published articles assessing the effectiveness of Behaviour Based Modelling have revealed that it is paramount in transforming employee attitude and hence reduce occupational related accidents (Fox, Hopkins and Anger 2009).

\section{Methodology}

The study population for questionnaire surveys (determined from a pre-survey in the study area) involved all the 282 workers in the wet mill section and all the 318 in the dry ill section. It was vital to capture all workers because they were most directly involved in timber operations and hence most affected by occupational safety and health hazards in the various sections they operated in. The distribution of the self administered questionnaires in the wet mill sections was as follows: log $\operatorname{deck}(48)$, sorting(30), chipper/ frame saw (60), green chain(60), incinerator (30) and moulding (54) and in the dry mill: kilns (24, boiler( 18), reprocessing(51), finger jointing (99) ware-house (75) and dispatch (51). Information captured in the questionnaire included period of occupation in the section, frequency of hazard occurrence, occupational safety and health hazards, visible environmental pollution, frequency of safety inspections and talks and general understanding of the principles of behaviour based safety. Interviews were conducted to collect clear-cut information on the levels of awareness of the role of behaviour based safety in combating occupational accidents and environmental pollution. The key informants for the interviews included the non-machine operator (foreman), the production manager, the safety and health officer, line managers, the nurse-in-charge, the safety and health representatives among the workers as well as external offers from the National Social Security Authority and the Environmental Management Authority. Focus group discussions were used in the determination of levels of BBS awareness and these involved workers from different sectors of the company as well as management. Field observations were undertaken in the presence of the SHE officer who assisted in interpreting work behaviour. In this study, field observations were crucial as they provided first hand information on the actual behaviours of the workers and hence a number of days were set aside to actually monitor the workers' behaviours. Secondary data sources included the company's records and this is data on occurrence of occupational related accidents and major environmental spillages prior to introduction of behaviour based modelling. This is for trend analysis so as to assess the extent to which behaviour based modelling has succeeded in retarding lost time due to occupation related accidents. Data analysis was undertaken using SPSS for parametric and non-parametric tests such as correlations, ANOVA and chi-squared tests.

\section{Description of study area}

The pine division timber processing plant is located in the Manicaland province of Zimbabwe and employs approximately 4500 employees. It is the third largest producer of pine-swan timber in Zimbabwe producing approximately $20 \%$ of the country`s annual timber output. The pine timber processing plant is located $62 \mathrm{~km}$ North of Manicaland`s provincial city of Mutare. The altitude of the area varies between 1100 and 1600 meters above sea level and is found between longitude $32^{\circ} 44^{`}$ East Greenwich meridian and latitude $18^{\circ} 32^{`}$ South of the equator. The pine division plant is located in agro ecological region one where the annual mean rainfall is approximately $2200 \mathrm{~mm}$ (millimeters) with rainfall spread throughout the year. The area records an annual average high temperature of $29^{\circ} \mathrm{C}$ (degree Celsius) with South Easterly to South Westerly winds. The area housing the pine division plant experiences cold winters with minimum ground temperatures reaching up to $0^{\circ}$ $\mathrm{C}$ and in some years recording negative values. The area of land in the area is under pine plantations for 
commercial timber production, with the tree roots helping to bind the soil particles together thereby reducing soil erosion. Rivers found within the area drain into Save catchment with rivers such as Nyamuziwa, Kayirezi and Mare among others feeding into Odzi River. The predominant soil type found within the area are sand soils weathered from the dolerite and alluvium soils are found along the river banks. The vegetation of Nyanga district in which the plant is located, is part of the Eastern Zimbabwe montane forest-grassland mosaic, within the montane grasslands and shrublands. It is dominated by miombo woodlands (Brachystegia spiciformis, Brachystegia tamarindoides and Uapaca kirkiana), Syzygium woodlands of dwarf Msasa, Mulanje cypress, Tree ferns and forest tree fern among other species. The vegetation has been, however, disrupted by the forestry plantations leaving the black wattle and the pine being the dominant plant species. The explained vegetation supports a variety of animal species like baboons, kudus, elands and bucks among others.

The area houses approximately six thousand (6000) inhabitants with most of the economically active directly or indirectly employed under the processing plant. Apart from formal employment the community also practices subsistence farming and livestock rearing. In hard times the Nyanga pine community sustains their livelihoods through selling their produce at the nearby Nyanga town and also involved in poaching of animals found within the pine plantations.

\section{Results and discussion}

\subsection{Common types of hazards and pollutants in timber processing operations}

The Pine division was facing challenges in dealing with the prime cause of occupational health, safety and environmental problems whereas most of the causes were attributed to the inability to follow procedures and the use of short cuts. In the year 2009 the company introduced Behaviour Based Modelling as a way of curtailing occupational accidents and environmental problems encountered during timber processing. Wood dusts are a potential health problem when wood particles from processes such as sanding, smoothing and molding become airborne. Breathing such particles may cause allergic respiratory symptoms, mucosal and non allergic respiratory symptoms. Sawdust also deters vision as it pollutes the air forming a thick film which obscures vision exposing employees to accidents. The cyclone sucker in the dry mill section at the pine timber processing plant is malfunctional and this has resulted in employees being exposed to the effects of wood dust. Wood dusts also cause eye irritation, nasal dryness and frequent dryness of the respiratory system.

Clinical health records revealed that respiratory infections were high in the wood sector especially among workers whose employment time frame was in range of zero and five (0-5) years, moderate in age range 6$15 y e a r s$ and low among 16 years and above. This implies that employment time frame was sensitive to wood dust thus with time employees adapts to the conditions as shown by low frequency amongst those above sixteen years. Respiratory infections such as nasal irritation, wheezing, headaches and eyes irritation cases had been reported by $88 \%$ of employees in the factory. Machine operators (36\%), assistants (24\%) and graders (19\%) were the most susceptible and general workers least susceptible to respiratory infection. Onsite direct observations revealed that housekeeping procedures have not been taken seriously as wood shavings and saw dust were seen accumulating around circular and band saws. Timber processing operations expose employees to various forms of accidents during servicing of machinery and the processing of timber. Traumatic occupational injuries in the timber sector represent significant public concern. Timber related accidents induce emotional and financial costs to both families and society. Accidents are experienced usually inform of cuts and burns. Table 1 shows some of the most common accidents and injuries encountered during timber processing operations at pine timber processing plant.

Table 1: Common accidents and injuries at the timber processing plant

\begin{tabular}{llrr}
\hline Hazard & Accidents & Total recorded 2005-2011 & \% of recorded accidents \\
\hline Steps/stairs & Slips, trips and falls & 78 & 12.5 \\
Conveyors & Slips, trips and falls & 22 & 3.5 \\
Log storage & Falling logs from unstable stacks & 129 & 20.7 \\
Access ways & Slips, trips and falls & 34 & 5.5 \\
Portable ladders & Falls & 66 & 10.6 \\
Walkways & Slips on slippery surfaces & 26 & 4.2 \\
Service platforms & Slips and falls & 39 & 6.3 \\
Raised walkways & Falls & 19 & 3 \\
Tarping wood stacks & Slips and falls & 77 & 12.4 \\
Timber stacking & Collapse of unstable stacks & 124 & 20 \\
Moving vehicles & Crushing or being run down & 9 & 1.4 \\
& Total & 623 & $100 \%$ \\
\hline
\end{tabular}


Data from Table 1reveals the most common types of hazards associated with timber processing operations. It is observed from Table 1 that the highest accidents are associated directly or indirectly with timber stacking and this is due to employee attitude towards heights and failure to follow stacking procedures.

The data in Figure 2 shows the common accidents associated with timber processing and the percentage affected.

\subsubsection{Musculoskeletal disorders}

Musculoskeletal disorders in timber processing are mainly as a result of poor man-machine interface. Hickman and Geller (2003) argued that although the global

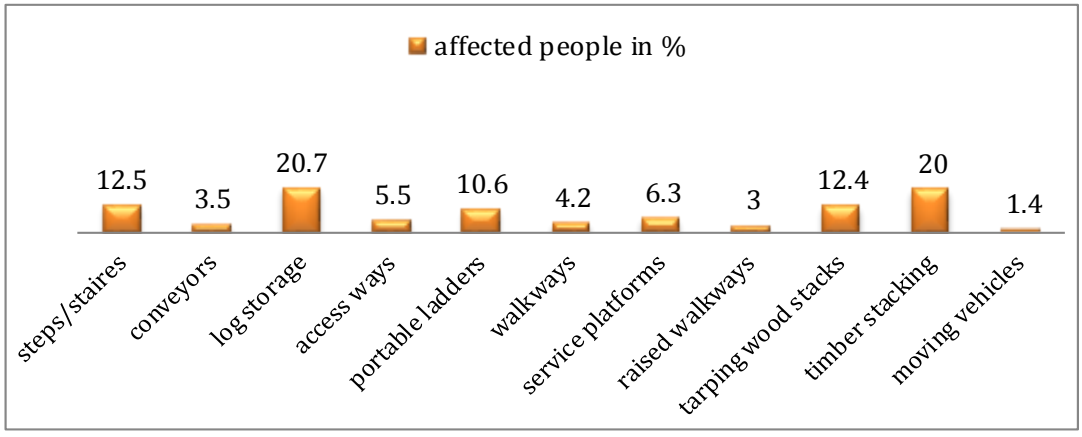

Figure 2: Common accidents and injuries in percentage industrialisation and innovative technologies have their advantages, they can bring inherent ergonomic hazards at workplaces. For instance although they increase efficiency they have the potential to cause painful and sometimes debilitating injuries known as Work Related Musculoskeletal Syndrome Disorders. These disorders are not felt immediately but they affect employees even in the long run for example back pains upon retirement. To meet the production requirements of a, shift employees overlook or ignore the operational procedures resulting in musculoskeletal disorders. In the timber processing operations at the plant in Eastern Zimbabwe, musculoskeletal disorders are largely as a result of the working positions of employees. In some instances employees spend much of their time working in positions that are detrimental to their health thus causing musculoskeletal disorders. Onsite observations revealed that repetitive tasks, lifting of heavy planks of timber to feed milling machines and poor working postures poses a health risk hazard to employees. Graders, machine operators are the major groups of workers prone to Work Related Musculoskeletal Syndrome Disorders (WRMSSDs).

Table 2: Frequency of work related musculoskeletal syndrome disorder (WRMSSD) at the plant

\begin{tabular}{lr}
\hline Work related musculoskeletal syndrome disorder & Number of workers affected \\
\hline Low back pain & 48 \\
Chest pains & 26 \\
Cramps (legs and hands) & 16 \\
Neck pain & 21 \\
\hline
\end{tabular}

\subsubsection{Noise}

Noise is any sound pressure variation in the air or other or other medium that can be detected by the human ear. Noise induced hearing loss (NIHL) is the most serious adverse health effect of noise and a compensable occupational disease. Machinery involved in timber processing such as chain saws, chipper canters and side loaders produce high noise levels. In some instances the noise levels of machinery exceed the stipulated $90 \mathrm{db}$ for an 8 hour shift by up to $120 \mathrm{db}$ and thus becoming an occupational health hazard. The unavailability of the required Personal Protective Equipment or Clothing (PPE/C) at the Pine processing plant such as ear guards results in employees suffering the adverse impact of noise pollution. The impact can either be immediate or long term.

\subsubsection{Oil spillages, sawdust and boiler effluent}

Oil spillages and boiler effluent are the most common types of environmental problems associated with timber processing plant's operations. Oil spillages are produced from the machines during servicing and moving automobiles during refueling. Boiler effluent must be dealt with cautiously to ensure that it will not pollute the local streams and rivers. Direct observations revealed that wastes from sawmills especially sawdust still pose a serious environmental threat at the pine plant, since they are simply dumped on sites, discarded to the stream, or merely burnt, hence inflicting dreadful stream as well as air pollution. Sawdust and wood waste that is generated during timber processing is dumped around the nearby areas and some ends up in Odzi River. Over a period of time the wood waste decomposes and emits methane, a greenhouse gas that is 21 times more harmful to the environment (Owusu et al 2011). These wastes deposits into or new water course can alter, disrupt or destroy fish habitat, decreasing fish variety and abundance. Additionally water runoff from exposed piles of unburned and partially burned wood waste is contaminating nearby streams and the surroundings. Ground water contamination may also result from leaching of tannic acids resulting from biological degradation of sawmills (Amerasekera and Jayaratna 2002). 


\subsubsection{Levels of awareness in behaviour based modelling}

Data obtained from the interviews and questionnaires responded to indicate that most of the employees are aware of the existence of Behaviour Based Modelling and its purpose in accident and environmental pollution prevention. It was however, revealed from some of the interviews that employees who join the company to cover up posts which would have opened up do not have the opportunity to undergo Behaviour Based Modelling training and therefore are not aware of Behaviour Based Modelling and its intended goals. Interviews and direct observations also realised that employees always have pre-shift talks where they brainstormed about occupational safety and environmental issues. These pre-shift talks are a tool used to raise employee awareness of Behaviour Based Modelling and its purpose. Of the 114 questionnaires responded and returned a total of 107 employees underwent Behaviour Based Modelling training and understand fully the purpose of the training.

\subsubsection{Level of behaviour based modelling awareness by section}

The wet-mill section has the highest number of the untrained employees and thus some of the employees in this section do not fully understand the purpose of Behaviour Based Modelling. It was also established that although employees are fully aware of the underlying principles of Behaviour Based Modelling they are in some instances forced to compromise their safety due to lack of resources. In most organisations management considers production to be at the centre stage while sidelining safety and environmental management issues (Hickman and Geller 2003). Despite having gone through Behaviour Based Modelling training fellow work-mates are there as on lookers instead of acting as brother's keeper as in the principles of Behaviour Based Modelling. This plate serves to illustrate that despite having gone through Behaviour Based Modelling training some employees are reluctant to fully implement its principles due to shortage of machinery and equipment. Direct observations and questionnaire responses from the Dry-mill section revealed that employees in this section follow all procedures thus they are aware and understand the concept of Behaviour Based Modelling. Despite the existence of some loopholes the research established that approximately $95 \%$ of all the employees are aware of the concept of Behaviour Based Modelling and understand the under lying principles.

5.1.6 The role of behaviour based modelling in combating occupational related accidents and environmental pollution

Statistics on safety performance at pine timber processing company showed that Behaviour Based Modelling plays a significant role in accident and environmental pollution reduction. The number of occupational related accidents and environmental spillages recorded since the inception of Behaviour Based Modelling has continuously been declining.

Table 3: Accident statistics prior and after the inception of behaviour based modelling according to gender and year of accident occurrence

\begin{tabular}{lrrrr}
\hline Year & \multicolumn{2}{c}{ Total recorded accidents } & Total \\
& Males & Females & 7 & 110 \\
2005 & & 103 & 9 & 118 \\
2006 & 109 & 6 & 114 \\
2007 & & 108 & 9 & 116 \\
2008 & BBM launched & 107 & 4 & 64 \\
2009 & & 60 & 2 & 52 \\
2010 & & 50 & 1 & 49 \\
2011 & & 48 & & \\
\hline
\end{tabular}

In the year 2009 the processing plant put into operation Behaviour Based Modelling in an endeavor to reduce accidents at the workplace. The years 2005 , 2006, 2007 and 2008 recorded 110,118,114 and 116 accidents respectively. As shown in Figure 3, prior to the introduction of Behaviour Based Modelling, the timber company

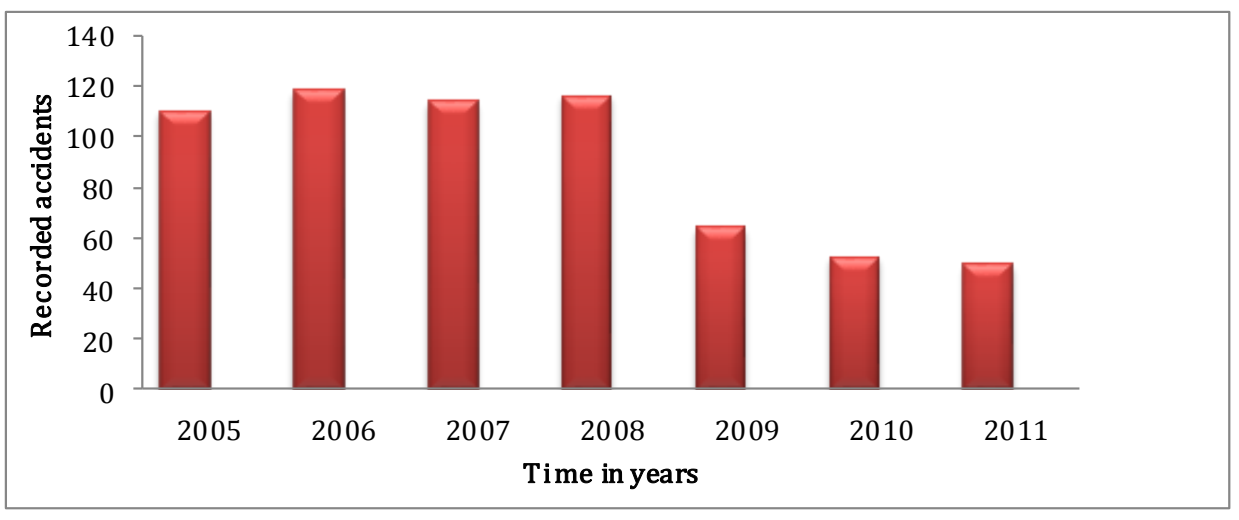

Figure 3: Accident statistics at the pine timber processing plant 
recorded high numbers of accidents and the introduction of Behaviour Based Modelling has seen the company recording double figured accidents a thing which was never known to be possible within the organisation. The introduction of Behaviour Based Modelling resulted in a decline of work related accidents with the year 2009 recording a total of 64 accidents a number 52 times lower than the 116 accidents recorded in the previous year (2008). In an interview with the SHE officer, it was learnt that the introduction of Behaviour Based Modelling transformed management attitude towards the procurement of Personal Protective Equipment/Clothing. The availability of PPE/C in the year 2009 was essential and played a vital role in reducing the number of occupational accidents to 64. It remains the goal of the SHE department to "achieve a zero target" in accident prevention. The National Social Security Authority personnel also revealed in an interview that the pine timber processing plant has seen a decline in the number of reportable accidents since the year 2009 though they are not familiar with the cause of the decline.BBM has managed to retard the occurrence of occupational accidents at Nyanga Pine as observed with the decline in accident prevalence.

\subsubsection{Environmental spillages statistics prior and after the inception of behaviour based modelling}

The Pine timber processing plant was the major polluter of the nearby Odzi River and to curtail this problem there was need for a comprehensive environmental management strategy. The introduction of Behaviour Based Modelling managed to instill a sense of ownership in terms of natural resources among employees. Behaviour Based Modelling managed to teach employees of the necessity of sustainably managing natural resources. This resulted in the engineering department putting in place an oil separator which ensures that oils are removed from the water before it is disposed into the nearby river hence ensuring sustainable management of the water resource. The introduction of Behaviour Based Modelling resulted in a reduction in the total number or recordable spillages as shown in Table 4.

Table 4: Recordable spillages

\begin{tabular}{|c|c|c|}
\hline Year & & Recordable spillages \\
\hline 2005 & & 5 \\
\hline 2006 & & 4 \\
\hline 2007 & & 5 \\
\hline 2008 & & 6 \\
\hline 2009 & BBM launched & 3 \\
\hline 2010 & & 1 \\
\hline 2011 & & 0 \\
\hline
\end{tabular}

The introduction of BBM managed to retard recordable spillages from 6 in the year 2008 to 0 by the end of 2011 . An interview with EMA personnel made known that the water quality in Odzi River has improved since the year 2009. Added to this it was also revealed that since the same year 2009 timber processing plant has been observed as the most improved organisation in terms of environmental management among the timber producing companies in the region.

Figure 4 shows that recordable spillages were high before the inception of Behaviour Based Modelling and the introduction of Behaviour Based Modelling managed to reduce the number of recordable spillages to 0 by the year 2011. The reduction of environmental spillages to 0 serves to demonstrate the role Behaviour Based Modelling is playing in

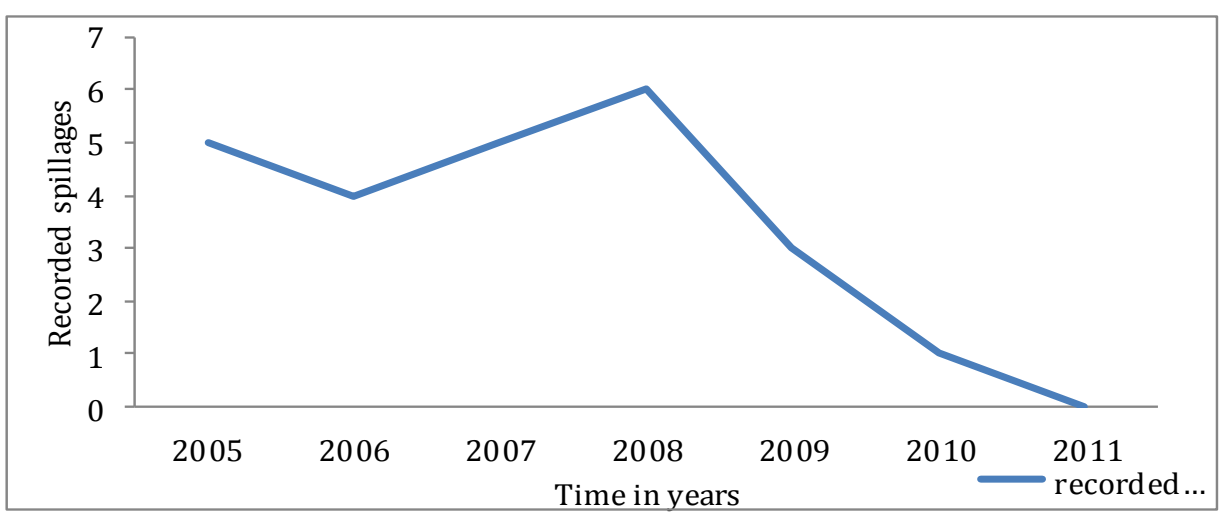

Figure 4: Recordable spillages compacting environmental pollution at the timber processing plant.

\subsubsection{The effectiveness of behaviour based modelling in retarding lost time injuries}

Lost Time Injuries (LTI) are detrimental to the organisation since they increase down time thereby retarding production. LTI's are also an expense to the organisation because they result in the Company losing a lot of money towards health expenses. According to the National Social Security Authority standards, a company with 
a high number of LTI`s is regarded an unsafe working environment and hence the introduction of BBM was also aimed at retarding LTI's.

Table 5: Recorded injuries and lost time injuries

\begin{tabular}{|c|c|c|c|}
\hline Year & & Total recorded injuries & Lost Time Injuries \\
\hline 2005 & & 110 & 96 \\
\hline 2006 & & 118 & 90 \\
\hline 2007 & & 114 & 94 \\
\hline 2008 & & 116 & 82 \\
\hline 2009 & BBM launched & 64 & 55 \\
\hline 2010 & & 52 & 49 \\
\hline 2011 & & 49 & 31 \\
\hline
\end{tabular}

Data from Table 5 shows the relationship between total recorded injuries (TRI) and lost time injuries (LTI) and how they both respond to the introduction of Behaviour Based Modelling. The introduction of Behaviour Based Modelling saw a reduction in both TRI and LTI with the involvement of every worker so that they become part of the system. Becoming part of the system enabled employees to monitor fellow employees and this resulted in LTI reducing from 82 in 2008 to 55 in 2009 a difference of 27 LTI within a year. A correlation test using Pearson's Product Moment Correlation Co-efficient revealed that there was a strong relationship between total recorded injuries and lost time injuries with correlation significant at 0.9. This shows that when TI is low LTI also becomes low and as derived from existing literature the ability of Behaviour Based Modelling to retard and eliminate occupational injuries also ensures retardation in lost time injuries. The SHE officer at the pine timber division also acknowledged that the use of Behaviour Based Modelling has enabled the company to comply with other management systems such as the Environmental Management System (ISO 14001).

\section{Conclusion}

The Behavior Based Modelling programme is crucial in occupational safety and health and environmental management. Behaviour Based Modelling has succeeded in transforming the manner in which the pine timber division dealt with occupational safety, health and environmental management issues. Behaviour Based Modelling has changed employee attitudes in dealing with occupational related accidents and environmental pollution through the "brother`s keeper" attitude. Prior to the introduction of Behaviour Based Modelling, the pine timber processing company faced challenges in dealing with occupation related accidents and environmental management problems. Before the implementation of Behaviour Based Management, the pine processing plant recorded high numbers (triple figured digits) of near misses and occupational related accidents. However, the introduction of Behaviour Based Modelling resulted in the recording of double figured digits in occupational related accidents and zero major environmental spillages by the end of 2016. This serves to demonstrate that Behaviour Based Modelling is effective despite the fact that it needs improvement in some areas so as to be able to achieve a zero target.

Behaviour Based Modelling has assisted employees in hazard identification in their areas of jurisdiction thereby reducing accident occurrence. Timber processing operations are associated with occupational hazards such as high levels of noise, chemicals, dust, high temperatures and improper man-machine interface. Behaviour Based Modelling is helping management in to looking out for opportunities to improve in safety and health issues since all employees have a transformed attitude towards accident management and environmental pollution control. The introduction of Behaviour Based Modelling has also seen the reporting and recording of near misses a thing which was never known to exist within the division. The level of awareness of Behaviour Based Modelling is satisfactory amongst employees since some employees are very aware of the role of Behaviour Based Modelling at workplace. The study revealed that there were positive results of BBM intervention as noted by the reduction in both occupational related accidents and recordable environmental spillages.

The management at timber processing plant needs to offer incentives at divisional level for outstanding safety and environmental performance. Twined to this the procurement of PPE/C must be improved so as to allow the outright applicability of Behaviour Based Modelling. Employees need to report all unsafe conditions, all unsafe acts, injuries and accidents at the workplace and this can arouse for corrective action by management. Employees must also read and understanding warning signs, use of personal protective equipment or clothing appropriately to avoid unsafe acts. Respiratory diseases and backache are still a problem at the pine timber processing plant although they are declining since implementation of BBM. In addressing backache problem the SHE department together with the engineering department should come up with lifting procedures which must be accessible to everyone. SHE department must educate people about the correct and consistent use of the dust masks and encourage employees to use it within the required period. Hence continuous training of employees 
helps occupational safety and health management. The SHE department should ensure that employees have the right to refuse to work under unsafe and unhealthy work conditions. Management must ensure that hazards and risks are eliminated prior to employees commencing the work. To ensure maximum compliance to legislation at workplace, the SHE department should induct all employees about the applicable legislations such as Environmental Management Act (EMA) chapter 20:27. Refresher induction must also be conducted after a certain period of time. Management representatives are also supposed to attend workshops which are conducted by organisations such as NSSA and Ministry of Environment and natural resources.

NSSA must ensure prescription of guidelines and codes of practice on the management of occupational health and safety in the workplace which provide for effective monitoring, surveillance, diagnoses, and prevention of occupational injuries and diseases. NSSA factory inspectorate should increase the frequency of inspections and penalties such that firm's compliance to regulations improves on time. More so, NSSA must ensure functional competence and expertise of all employees through training and human resource development and ensures that employees are provided with adequate protection clothing. This will ensure the constant review of the Behaviour Based Modelling programme.

\section{References}

Amarasekera, R.M and Jayaratna, P. (2002). Resource Potential and its Spatial Distribution in the Kandy District, Integrated Development Association, Kandy.

Bandura A (2007). A Social Learning Theory London, Prentice Hall, Englewood Cliffs.

Byron N T (2002). A Tool to Assess Aspects of an Organisation's Health and Safety Climate, Edinburgh, PRISM Seminar.

Colman, P. Ezinah, F. and Wezet, G. (2007). Occupational and Health Problems among Wood Processing Enterprises in Libreville, Gabon, African Newsletter on Occupational Health and Safety. 17 (2):44-7.

Cooper M, Philips R, Sutherland V J and Makin P J (2004). Reducing accidents using goal setting and feedback: a field study. Journal of Occupational and Organisational Psychology London, Prentice Hall.

Cooper, D. (2000). Discussion forum at http://www.behaviouralsafety. Date accessed: 01.03.2012.

Cox, S and Cox, T (2000). Safety, Systems and People, London, Butterworth Heinemann.

Daniels, A C (2004). Performance Management. Tucker, GA: Performance Management Publications

DePasquale J and Geller E (1999). Critical success factors for behavior-based safety: a study of twenty industrywide applications. Journal of Safety Research 30, https://doi.org/10.1016/S0022-4375(99)00019-5

Fishwick, A H and Ormond, J M and Chem, E (1998). Stop Tomorrow's Injuries Today, Safety '98. Rugby, England.

Fleming, M and Lardner, R (2005). Behavioural Modification Programmes. Establishing Best Practice. Scotland, Edinburgh, The Keil Centre.

Fox, D. K, Hopkins, B. L and Anger W K. (2002). "The Long-Term Effects of a Token Economy on Safety Performance in Open-Pit Mining." Journal of Applied Behavior Analysis, Vol. 20.

Fox, D.K., Hopkins, B.L., and Anger, W.K. (2009). The Long-Term Effects of a Token Economy on Safety Performance in Open-Pit Mining, Journal of Applied Behavior Analysis, 20: 215- 224. https://doi.org/10.1901/jaba.1987.20-215

Herman, V. (2000), Based Geometric Modeling in CAD, A New Approach", in proceedings of INES'2000, 2000 IEEE International Conference on Intelligent Engineering Systems, Ljubljana, Slovenia. 53-56.

Hickman, J.S. and Geller, S.E. (2003). A Safety Self-Management Intervention for Mining Operations. Journal of Safety Research. 34: 299- 308. https://doi.org/10.1016/S0022-4375(03)00032-X

Horvath, L. and Rudas, I. J (2010). "Integrated Associative Modeling of Parts and their Machining Process by Features", in proceedings of the ICMT 2010 conference, Singapore: 316-321.

Jones, B., Cox, S., Rycraft, H., (2004). Assessing employee attitudes towards behavioural approaches to safety management within UK reactor plants. In: Proceedings of the PSAM7/ESREL'04 Conference, https://doi.org/10.1007/978-0-85729-410-4_254

Lardner, R (2002). Team working and Safety, Improving Safety: Cultural and Organisational Factors, Keil Centre, PRISM Seminar

Nhete, T. (2000). Biomass energy in Zimbabwe, Harare: Nehanda Publishing House.

Nyamapfeni, K. (1991). Soils in Zimbabwe, Harare: Nehanda Publishing House.

Schutte, P. (1998). The Human Factor in Safety: A Behavior-Based Approach Enhancing Empowered, Valued and Safety Committed Employees, Mine Safe International 1998: 219 -228.

Sulzer A B (2001). The Modification of Occupational Safety Behaviour. Journal of Occupational Accidents, Vol 9. 